\title{
Inteligência Swarm e Equilíbrio de Verhulst Aplicados à Alocação de Potência em Redes Ópticas CDMA Particionadas
}

\author{
Moanir Stábile Filho, Taufik Abrão ${ }^{1}$ \\ Lucas Dias Hiera Sampaio ${ }^{2}$
}

\begin{abstract}
A utilização da técnica de acesso múltiplo por divisão de códigos (CDMA) em redes puramente ópticas foi proposta levando-se em consideração sua ampla largura de banda óptica. O CDMA óptico é uma técnica que permite a múltiplos usuários compartilharem simultaneamente o mesmo canal de fibra de modo assíncrono sem delay e sem a necessidade de gerenciamento de recursos (scheduling). No entanto, os níveis de interferência de múltiplo acesso (MAI) são significativos nesses sistemas devido à natureza da detecção de potência incoerente. A redução desse efeito de interferência é crucial na melhoria de desempenho dos sistemas CDMA ópticos. Neste sentido, propõe-se a utilização de mecanismos de alocação de recursos, particularmente de potência, que garantam a cada usuário um desempenho mínimo aceitável em termos de taxa de erro de bit (BER). Na estratégia de controle de potência centralizado é necessário que um nó central tenha informações sobre o ganho de todos os links. Por sua vez, no controle de potência particionado (rede de acesso e rede de broadcast) verifica-se que os sinais ópticos após o acoplador estrela não contribuem na determinação da MAI e por conseguinte não afetam o balanço de potência associado a cada laser. Neste trabalho, analisa-se o problema do controle de potência para redes ópticas CDMA particionadas (p-OCDMA), sob dois pontos de vista distintos: a) modelo matemático de crescimento populacional de Verhulst, discutido em [1]; b) abordagem heurística denominada inteligência swarm (PSO - particle swarm optimization). Extensivas simulações e resultados numéricos indicaram que tanto o modelo de Verhulst quanto o PSO são adequados para resolver o problema do controle de potência em redes p-OCDMA, sob o ponto de vista da otimização uni-objetivo, com resultados de convergência satisfatórios para uma variedade de cenários de operação para o sistema p-OCDMA. Finalmente, uma análise de complexidade em termos de número de operações, é realizada no sentido de obter uma quadro comparativo mais realista para as duas metodologias de otimização, indicando claramente a superioridade da abordagem analítica-iterativa da abordagem de Verhulst.
\end{abstract}

Palavras-chave: CDMA óptico, alocação de recursos, controle de potência, modelo de Verhulst, otimização uni-objetivo, inteligência computacional swarm.

\footnotetext{
${ }^{1}$ Departamento de Engenharia Elétrica, Universidade Estadual de Londrina, 86051-990, PR.

\{moanir@gmail.com\} \{taufik@uel.br\} www.uel.br/pessoal/taufik

${ }^{2}$ Departamento de Ciência da Computação, Universidade Estadual de Londrina, 86051-990, PR.

\{lucas.dias.sampaio@gmail.com\}
} 
Abstract: The deployment of code division multiple access (CDMA) technique in optical networks was proposed taking into account the huge optical spectrum availability. In the optical CDMA (OCDMA) systems, multiple users simultaneously sharing the same optical asynchronous channel with neither the necessity of time coordination nor scheduling of resources. However, the attainable levels of multiple access interference (MAI) are a concern, due to the characteristic of the non-coherent power detection associate to the optical signal. The reduction in the MAI effects is crucial in order to achieve performance improvement in these systems. Hence, in this work we propose the use of resource allocation, particularly the power allocation within the lasers, that guarantee a minimum acceptable performance in terms of bit error rate (BER). In the centralized power control strategy, the central node coordinates the gain link of all active nodes in the system. On the other hand, in the partitioned power control optical networks (divided in access and broadcast network sides) the optical signals after the star coupler do not contribute to increase the MAI; as a consequence, the broadcast network side does not affect the power balance associated to each laser from access network side. In this work, the power control problem in partitioned optical CDMA (p-OCDMA) networks is analysed under two distinct approaches: a) based on the Verhulst mathematical model originally conceived for population growth, and discussed in [1]; b) heuristic approach named swarm intelligence (PSO - particle swarm optimization). Extensive simulations and numerical results have indicated that both the Verhulst as the PSO models are adequate in order to resolve the optimization power problem in p-OCDMA networks. The optimization was carried out under the single-objective optimization (SOO) framework, with suitable convergence results for both approaches and considering various p-OCDMA system operation scenarios. Finally, a computational complexity analysis is presented in terms of both iterations toward convergence and number of operations. As a consequence, a more realistic comparative framework is provided for both optimization methodologies, revealing clearly the superiority of the Verhulst analytical-iterative approach.

Keywords: Optical CDMA, resource allocation, power control, Verhulst equilibrium equation, single-objective optimization, swarm intelligence.

\section{Introdução}

Com o intuito de tornar mais útil o uso de toda a largura de banda disponível nas redes ópticas, estudos mostram que CDMA óptico oferece uma solução interessante para redes de múltiplo acesso. Muitas alternativas para aumentar a eficiência espectral das redes ópticas e otimizar a utilização de sua enorme largura de banda foram sugeridas, entre elas: acesso múltiplo por divisão de comprimento de onda (WDMA) utilizando multiplexadores add-drop reconfiguráveis, acesso múltiplo por divisão de tempo óptico (OTDMA) e acesso múltiplo por divisão de código óptico (OCDMA) [2, Cap.3-6]. Em um sistema OCDMA 
diferentes transmissores fazem o uso de códigos diferentes para espalhar seus dados, tanto no domínio do tempo como no domínio da frequência. Os códigos são cuidadosamente projetados para que muitos transmissores possam transmitir simultaneamente sem interferir um no outro, e o receptor pode selecionar o sinal transmitido desejado decodificando adequadamente o sinal recebido [3]. OCDMA permite acesso simultâneo à rede por múltiplos usuários e possui muitas vantagens, tais como, soft capacity, transmissão de pacotes robusta, atraso de pacotes desprezível e operação assíncrona [4]. Então, OCDMA é considerado como uma das principais tecnologias futuras para tráfego multimedia suportando vários níveis de QoS. Todos os sistemas OCDMA sofrem do problema de near-far onde os nós mais próximos tem suas potências muito mais superiores do que as potências dos nós mais distantes. Portanto, transmitir o controle de potência foi sugerido para as redes OCDMA para equalizar a potência recebida de todos os usuários resultando em um considerável ganho de capacidade, já que esse controle de potência se mostrou bastante eficiente nos sistemas sem-fio [5]. Para redes OCDMA com nível de QoS igual para todos os terminais e todos os nós localizados a uma mesma distância do acoplador estrela, o controle de potência pode ser desprezado. Devido ao aumento da demanda de vários níveis de QoS, assim como nós muito espalhados geograficamente, o controle de potência será um ponto crítico em redes OCDMA. Implementando sistemas com vários níveis de QoS faz as redes ópticas muito mais eficientes devido a otimização dos recursos disponíveis [6].

A interferência de múltiplo acesso (MAI) pode ser bem elevada se comparada a sistemas CDMA sem-fio. O controle de potência suaviza o MAI, aumentando a performance e throughput da mesma forma que nos sistemas CDMA sem-fio. O controle de potência centralizado oferece ótima potência de transmissão distribuído entre os nós transmissores que tentam maximizar a relação portadora-interferência (CIR) desejada. No entanto, o controle de potência centralizado tem a desvantagem da necessidade de um nó central com informação sobre o ganho de todos os links.

Trabalhos anteriores considerando o problema do controle de potência em sistemas OCDMA estrela incluem [7], [6], [8], onde foram encontradas várias alternativas para a solução desse problema. Em [7] foi proposto o particionamento da rede estrela em duas: rede de acesso e rede de broadcast. Assim cada usuário poderia ser equipado com a informação do status dos outros nós, isso permite a distribuição de potência apropriada para suportar o balanceamento de potência. Já em [6] foi investigado o efeito da não-linearidade do fotodetector utilizando potência de transmissão ótima em uma rede OCDMA. O controle de potência nãolinear óptico foi resolvido por repetições de um algoritmo proposto que converge a um ponto único. Em [8] é utilizada uma técnica muito eficiente para a redução/eliminação da MAI, denominada spectral amplitude coding (SAC) que se mostrou também vantajosa para o controle de potência, sem tornar o decodificador mais complexo em relação ao decodificador na ausência de mecansimos de controle de potência. 
Analogamente, o problema de alocação de recursos tem sido formulado para atender requisitos de sistemas de comunicação sem fio de multiplo acesso [9-12]. Especificamente, em [11], a formulação do problema de minimização da potência em redes DS/CDMA sem fio, proposta em [9], foi estendida para um ambiente CDMA sem fio de múltiplas taxas, i.e., um ambiente de comunicação multimídia com distintos QoS. Em [12], o problema multiobjetivo da alocação de potência e taxa em redes sem fio de multiplo acesso por divisão de código é resolvido empregando-se a abordagem heurística por inteligência swarm.

O problema mais geral de alocação de recursos (particularmente potência e taxa) em sistemas de comunicação pode ser examinado segundo uma abordagem de otimização conjunta mais ampla, denominada otimização multi-objetivo (MOO - multi-objective optimization), tendo em vista a minimização da potência de transmissão em cada transmissor (laser) e simultaneamente a maximização da capacidade (throughput) do sistema de múltiplo acesso (particularmente o p-OCDMA). A abordagem MOO consiste na busca de soluções ótimas de compromisso, i.e., leva em consideração diferentes objetivos contraditórios. A partir da obtenção de um conjunto de soluções ótimas, denominado conjunto ótimo de Pareto (Pareto optimal ou ainda Pareto front), onde cada solução é tão eficiente quanto as demais, ou seja cada solução do conjunto é considerada ótima em um sentido específico, dependendo da maior ou menor importância relativa atribuída a cada objetivo individualmente, o decision maker poderá então selecionar a solução que melhor cumpre com as exigências e condições da rede OCDMA.

A formulação do problema mais geral da alocação de recursos em um sistemas de comunicação de múltiplo acesso OCDMA pode ser expressa através dos seguintes objetivos conjuntos:

a) minimizar a potência transmitida;

b) maximizar a capacidade do sistema (throughput).

c) minimizar a probabilidade de outage;

Claramente, os três objetivos acima são conflitantes entre si e portanto, pode ser resolvido aplicando-se otimização multi-objetivo. Assim, reduzindo-se a potência transmitida (objetivo (a)) conduz a uma redução na taxa de dados e/ou da SNR (objetivo (b)); usuários com throughput elevado (objetivo (b)) ocupam maior parte dos recursos disponíveis no sistema, causando elevado outage (objetivo (c)) no sistema.

Na literatura, estes problemas geralmente são analisados separadamente, ou seja, buscase a otimização de um dos problemas ${ }^{3}$, considerando os outros dois problemas como restrições.

${ }^{3}$ Por exemplo a minimização de uma função custo baseada no objetivo a) ou ainda em c), ou alternativamente na maximização de outra função custo baseada no objetivo b). 
Duas formulações para esses problemas são amplamente utilizadas na literatura. A primeira é baseada na obtenção da potência ótima que maximiza o throughput total, atingindo o objetivo b), e considerando a SNR alvo e a potência transmitida como restrições. A segunda consiste em minimizar a potência total transmitida, alcançando o objetivo (a), considerando a SNR alvo e a taxa de dados como restrições [13].

A abordagem de otimização uni-objetivo mostrou-se suficiente para tratar o problema da minimização da potência em redes p-OCDMA, mantendo-se a SNR mínima como restrição. Este trabalho, inicialmente, analisa o problema de controle de potência em redes OCDMA particionadas utilizando-se o modelo de Verhulst, tendo-se como restrição uma SNR mínima e a solução do vetor potências transmitidas em um intervalo determinado pela máxima potência disponível em cada laser, e pelo limiar de detecção do receptor óptico. A solução do vetor de potência de Verhulst é comparando à solução analítica centralizada ${ }^{4}$, bem como à solução proposta em [7]. Em seguida, o mesmo problema de alocação de potência, na forma uni-objetivo com as condições conflitantes como restrições, é resolvido a partir do emprego de heurística do tipo inteligência social.

\section{Modelo do Sistema}

Seja a rede de comunicação CDMA óptica com topologia estrela $K \times K$ da Fig. 1 . Cada usuário possui dois links de fibra, um para transmissão e outro para recepção que podem ser conseguidos utilizando-se diferentes fibras ou diferentes comprimentos de onda. Para as fibras são considerados desprezíveis os coeficientes de dispersão e não-linearidade, somente a atenuação da fibra é levada em conta. Se as distâncias entre os nós e o acoplador estrela forem muito diferentes, como encontrado na prática, deverá ser considerado também o efeito near-far e algum tipo de controle de potência deverá ser aplicado para otimização do sistema.

Nesta análise [7], $\mathrm{Tx}_{i}$ é o transmissor e $\mathrm{Rx}_{i}$ é o receptor, como indicado na Fig. 1. No transmissor, os dados de cada usuário são convertidos do domínio elétrico para o óptico com o uso de um diodo laser e então codificados opticamente utilizando uma linha de atraso óptico para produzir o sinal OCDMA temporal. As potências dos lasers foram chamadas de $P_{i}$ para $i=1,2, \ldots, K$ usuários. O sinal óptico codificado CDMA sofre atenuação ao longo do enlace do nó com o acoplador estrela e depois pelo próprio acoplador estrela após transmitir o sinal para todos os nós através das fibras receptoras, com isso consegue-se ter sempre o sinal e a interferência sobrepostos desejados no nó receptor. Esse sinal composto é então decodificado por um filtro óptico compatível com o código do usuário desejado. As perdas de potência na codificação e decodificação ópticas foram consideradas iguais, então são somadas às outras perdas da fibra. Para um comprimento de fibra óptica total $L_{i j}[\mathrm{~km}]$

$\overline{{ }^{4} \text { Obtida a partir da inversa da matriz de canal. }}$ 
do $j$-ésimo nó Tx ao $i$-ésimo nó Rx, as potências de entrada e saída da rede são, [14]:

$$
P_{r}=a_{\text {estrela }} P_{t} \exp (-\alpha L),
$$

$\mathrm{e}$

$$
a_{\text {estrela }}=10 \log _{10} K-\left(\log _{2} K\right) 10 \log _{10} \gamma
$$

onde

$P_{r}=$ potência recebida;

$P_{t}=$ potência transmitida;

$\alpha=\frac{a}{10 \log (e)}$;

$a=$ coeficiente de atenuação da fibra $[\mathrm{dB} / \mathrm{km}]$;

$a_{\text {estrela }}=$ atenuação do acoplador estrela $[\mathrm{dB}]$;

$\gamma=$ relação de perda excessiva.

Na rede da Fig. 1, assume-se que todos os nós da rede estão distribuídos uniformemente em uma área centralizada no acoplador estrela com raio de $L_{\min } \leq r \leq L_{\max }$. O comprimento total da fibra conectando o $i$-ésimo nó receptor ao $j$-ésimo nó transmissor através do acoplador estrela pode ser representado por

$$
L_{i j}=L_{j}^{\mathrm{tx}}+L_{i}^{\mathrm{rx}} ; \quad i, j=1,2, \ldots, K,
$$

sendo: $L_{j}^{\mathrm{tx}}$ o comprimento de fibra do nó transmissor até o acoplador, e $L_{i}^{\mathrm{rx}}$ o comprimento de fibra do nó receptor até o acoplador. Neste caso, denomina-se $\mathbf{G}$ a matriz de atenuação da fibra que conecta todos os pares transceptores, podendo ser determinada substituindo-se (3) em (1)

$$
\mathbf{G}=\left[\begin{array}{cccc}
G_{11} & G_{12} & \cdots & G_{1 K} \\
G_{21} & G_{22} & \cdots & G_{2 K} \\
\vdots & \vdots & \ddots & \vdots \\
G_{K 1} & G_{K 2} & \cdots & G_{K K}
\end{array}\right]
$$

sendo $G_{i j}$ o elemento da matriz que representa a atenuação entre o nó $j$ Tx e o nó $i$ Rx.

Os codificadores ópticos da Fig. 1 codificam os bits dos dados numa série de pulsos ópticos de alta taxa utilizando as regras do Prime Code. O Prime Code gerado consiste de um conjunto de blocos contendo um único pulso. Para qualquer número primo $q$ um código consiste de $q$ blocos de duração $q$ chips. Um conjunto de sequências de códigos de duração $N=q^{2}$ foi derivado em [15]. Quando os $K$ usuários estão transmitindo simultaneamente, a interferência total em um dado receptor consiste da superposição de $K-1$ funções de correlação cruzada distintas. Para essa classe de sequiências de espalhamento, a variância para as amplitudes da correlação cruzada é de $\sigma_{C C}^{2} \approx 0,29$, a qual resulta independente de $q,[14]$. 
Inteligência Swarm e Equilíbrio de Verhulst Aplicados à Alocação de Potência em Redes Ópticas CDMA Particionadas

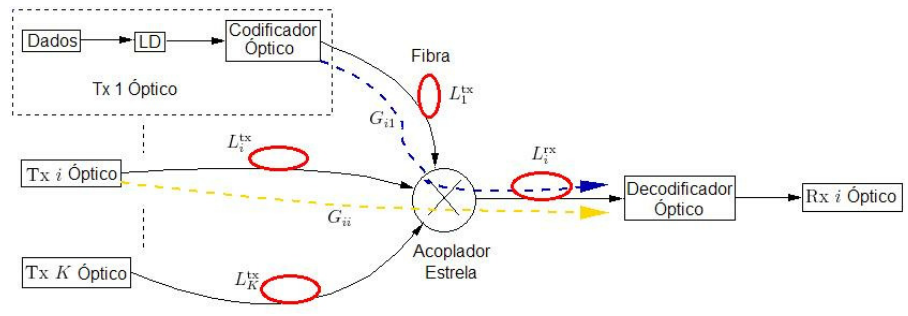

Figure 1. Rede CDMA Óptica em Estrela.

Admitindo-se controle perfeito de potência para todos os usuários ópticos, a relação sinal-interferência média $(\overline{S I R})$ é simplesmente,

$$
\overline{S I R}=\frac{q^{2}}{\sigma_{C C}^{2}(K-1)}
$$

Adicionalmente, utilizando aproximação Gaussiana quando um grande número de usuários ópticos estão ativos, a probabilidade de erro de bit pode ser aproximada por [16]:

$$
P_{E}=Q\left(\frac{\sqrt{\overline{S I R}}}{2}\right)
$$

\subsection{O Problema do Controle de Potência em Redes Ópticas}

O controle de potência óptico em uma rede é um problema de otimização. Denominandose $\Gamma_{i}$ a razão entre a potência da portadora pela potência da interferência (CIR) desejada à entrada do decodificador de interesse, tendo em vista obter uma certa Qualidade de Serviço (QoS) associada à taxa de erro de bit (BER) máxima tolerada para o $i$-ésimo usuário, e definindo-se o vetor-coluna $K$-dimensional da potência óptico transmitida $\mathbf{P}=\left[P_{1}, P_{2}, \ldots, P_{K}\right]^{T}$, então o problema do controle de potência óptico centralizada consiste em encontrar o vetor de potência óptico $\mathbf{P}$ que minimiza a função custo [17]:

$$
J(\mathbf{P})=\min \quad \mathbf{1}^{T} \mathbf{P}=\sum_{i=1}^{K} P_{i}
$$

sujeito às restrições:

$$
\begin{aligned}
\Gamma_{i} & =\frac{P_{i} G_{i i}}{\sum_{j=1 ; j \neq i}^{K} P_{j} G_{i j}+N_{i}} \geq \Gamma^{*} \\
P_{\min } & \leq P_{i} \leq P_{\max } \quad \forall i=1, \ldots, K
\end{aligned}
$$


onde

$\mathbf{1}^{T}=[1, \ldots, 1]$

$K$ = número de usuários ativos na rede óptica,

$G_{i j}=$ atenuação da fibra entre o $j$-ésimo nó transmissor e o $i$-ésimo nó receptor,

$N_{i}=$ potência do ruído no nó receptor $i$,

$\Gamma^{*}=$ CIR mínima,

Utilizando notação matricial, (8) pode ser expressa,

$$
\left[\mathbf{I}-\Gamma^{*} \mathbf{H}\right] \mathbf{P} \geq \mathbf{u}
$$

sendo $\mathbf{I}=$ matriz identidade, $\mathbf{H}$ = matriz interferência normalizada, cujos elementos são definidos por:

$$
H_{i j}=\left\{\begin{aligned}
0, & i=j, \\
\frac{G_{i j}}{G_{i i}}, & i \neq j,
\end{aligned}\right.
$$

e

$$
u_{i}=\frac{\Gamma^{*} N_{i}}{G_{i i}},
$$

em (12) tem-se a forma escalar do ruído. Resolvendo (10) substituindo a desigualdade por uma igualdade, obtém-se a solução do vetor potência ótimizada através da inversão de matriz:

$$
\mathbf{P}^{*}=\left[\mathbf{I}-\Gamma^{*} \mathbf{H}\right]^{-1} \mathbf{u}
$$

Tal vetor de potência óptico representa o caso de equilíbrio de potência no nó receptor, e é então a potência ótima exigida para alcançar a CIR desejada. Aumentando o valor da CIR resultaria em valores de potência óptica mais elevados que poderiam resultar maiores que a potência máxima permitida. Neste caso a solução seria fixar ou diminuir o valor da CIR desejada ou remover (desligar) alguns usuários da rede.

Ajustando a potência do ruído para zero e supondo equilíbrio perfeito da potência recebida em (8), pode-se considerar que a CIR máxima alcançável com limitada MAI é,

$$
\Gamma_{\max }=\frac{1}{K-1}
$$

Assim, a máxima CIR que pode ser alcançada na rede é limitada ao número de nós (independendo do comprimento da fibra), o qual é similar ao caso de uma única célula em um sistema de telefonia celular. Utilizando (14), a máxima $S I R$ alcançável é

$$
S I R_{\max } \simeq \frac{q^{2} \Gamma_{\max }}{\sigma_{C C}^{2}}=\frac{q^{2}}{(K-1) \sigma_{C C}^{2}}
$$


Inteligência Swarm e Equilíbrio de Verhulst Aplicados à Alocação de Potência em Redes Ópticas CDMA Particionadas

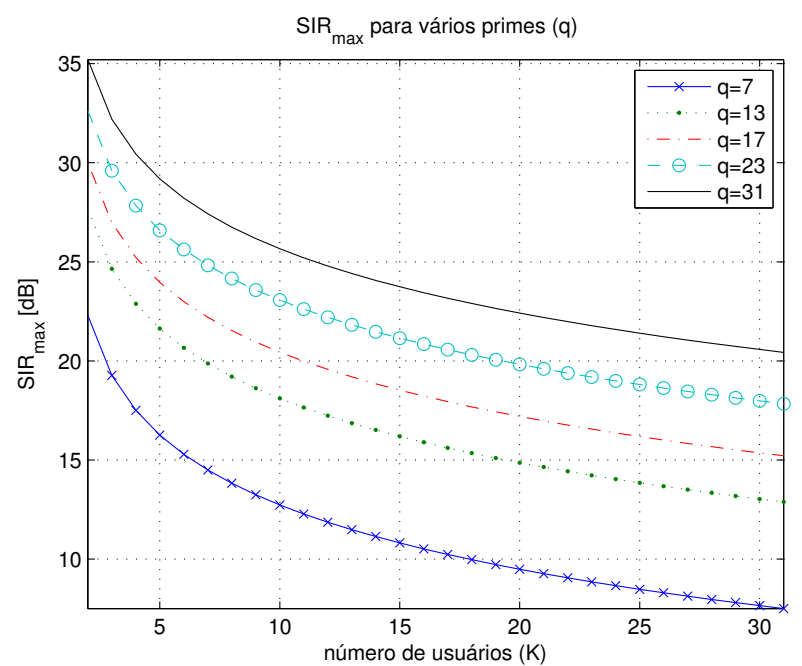

Figure 2. $S I R_{\max }$ para uma rede estrela para vários $q$, eq.(15).

Essa equação corresponde ao caso de usuários com potências iguais em (5). A Fig. 2 demonstra a variação da $S I R_{\max }$ de acordo com o tamanho da rede para diferentes valores de $q$ (Prime Codes). Assumindo-se $S I R_{\max }=20 d B$, e analisando o gráfico, pode-se afirmar que para $q=13$ a rede suporta no máximo 05 usuários do total de 13 usuários, enquanto que para $q=31$ a rede suporta todos os 31 usuários. Na rede óptica estrela da Fig. 1, a $S I R$ para o $i$-ésimo usuário relaciona-se à matriz de atenuação da fibra por:

$$
S I R_{i}=\frac{q^{2} G_{i i} P_{i}}{\sigma_{C C}^{2} \sum_{j=1, j \neq i}^{K} G_{i j} P_{j}+N_{i}}
$$

Desta forma, (16) pode ser utilizada em (6) para calcular a probabilidade de erro de bit da rede óptica CDMA estrela admitindo o emprego de seqüências do tipo Prime Codes, com ou sem controle de potência.

\section{Controle de Potência Óptico Particionado}

A avaliação da potência ótima pode ser simplificada empregando-se o particionamento da rede estrela em:

a) rede de acesso, incluindo o acoplador estrela, Fig. 3, 
Inteligência Swarm e Equilíbrio de Verhulst Aplicados à Alocação de Potência em Redes Ópticas CDMA Particionadas

b) rede de broadcasting, situada após do acoplador estrela.

A análise do efeito do particionalmento sobre a interferência de múltiplo acesso em redes OCDMA do tipo estrela foi tratado em [7]. A motivação principal para a adoção do particionamento na modelagem OCDMA com acoplador estrela se deve pela característica de isolação/separação dos sinais ópticos introduzida pelo acoplador, permitindo assim desprezar o efeito da MAI no trecho final da conexão (acoplador-receptor óptico).

Assumindo que $g_{j}=a_{\text {estrela }} \exp \left(-\alpha L_{j}^{\mathrm{tx}}\right)$ é a atenuação do nó transmissor mais perda do acoplador estrela e que $\hat{g}_{i}=\exp \left(-\alpha L_{i}^{\mathrm{rx}}\right)$ é a atenuação da fibra do nó receptor, a CIR no $i$-ésimo receptor é dada por:

$$
\Gamma_{i}=\frac{P_{i} g_{i} \hat{g}_{i}}{\sum_{j=1}^{K} P_{j} g_{j} \hat{g}_{i}-P_{i} g_{i} \hat{g}_{i}+N_{i}} \geq \Gamma^{*}
$$

com $G_{i j}=g_{j} \hat{g}_{i}$. Neste caso, os elementos da matriz interferência são dados por:

$$
H_{i j}=\left\{\begin{aligned}
0, & i=j \\
\frac{g_{j}}{g_{i}}, & i \neq j
\end{aligned}\right.
$$

Verifica-se que os cabos de fibra após o acoplador estrela não afetam a MAI encontradas pelos nós receptores [7].

Para a rede particionada da Fig. 3, pode-se definir dois valores de CIR: $\Gamma_{i}$ nos nós receptores e $\hat{\Gamma}_{i}$ na saída do acoplador estrela. Assim tem-se,

$$
\begin{aligned}
\Gamma_{i} & =\frac{P_{i} g_{i}}{\sum_{j=1}^{K} P_{j} g_{j}-P_{i} g_{i}+\frac{N_{i}}{\hat{g}_{i}}}, \\
\hat{\Gamma}_{i} & =\frac{P_{i} g_{i}}{\sum_{j=1}^{K} P_{j} g_{j}-P_{i} g_{i}}
\end{aligned}
$$

onde foi desprezado o ruído de fundo na segunda expressão. Adicionalmente, pode-se admitir $\Gamma_{i} \simeq \hat{\Gamma}_{i}$ se:

$$
\frac{N_{i}}{\hat{g}_{i}} \ll \sum_{j=1}^{K} P_{j} g_{j}-P_{i} g_{i}
$$

Portanto, em redes ópticas CDMA do tipo estrela com MAI limitada, a CIR necessária em cada nó receptor será a mesma daquela encontrada à saída do acoplador estrela: as fibras 
Inteligência Swarm e Equilíbrio de Verhulst Aplicados à Alocação de Potência em Redes Ópticas CDMA Particionadas

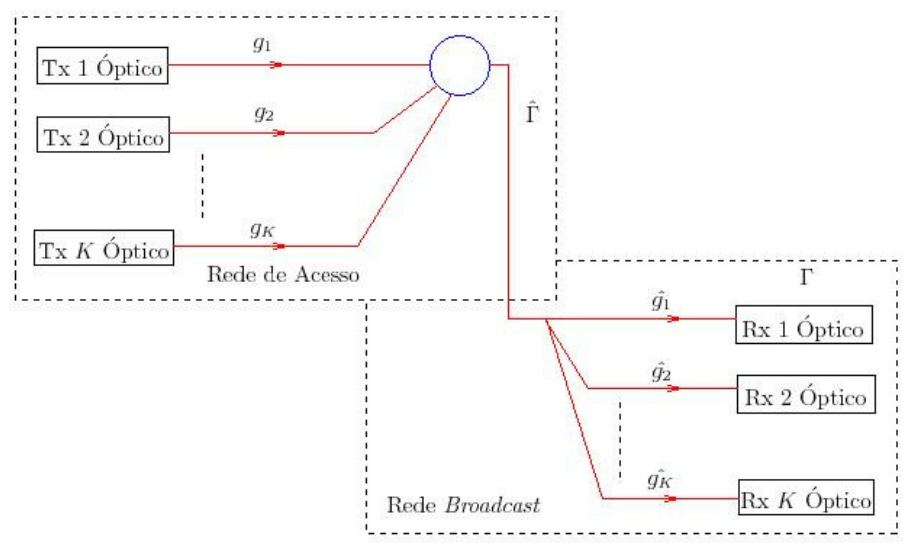

Figure 3. Particionamento da Topologia Estrela em Rede de Acesso e Rede Broadcast.

conectadas após o acoplador estrela não exercem efeito sobre o balanço das potências ótimas. Neste caso, a solução do problema do controle de potência é o autovetor correspondente ao maior autovalor associado à decomposição da matriz $\mathbf{H}$.

Então cada usuário pode avaliar a potência do laser óptico aplicado baseado em uma lookup table com os comprimentos das fibras de outros usuários e o status de cada usuário, se está ON ou OFF. A lookup table é atualizada regularmente e cada vez que o status de um usuário é modificado, o nível de potência ótimo é recalculado.

Empregando-se potências ótimas de laser, para uma dada taxa de erro de bit obtém-se o incremento na capacidade da rede (número de usuários) em comparação ao caso onde não se utiliza nenhum tipo de controle de potência.

\section{Otimização Uni-Objetivo para a Alocação de Recursos em Sistemas Ópticos}

Nesta seção, o problema da alocação de potência (minimização) é tratado na forma uni-objetivo, tendo as demais variáveis, tais como taxa de dados (ajustada por $R_{\min }$ ), QoS etc como restrição. Assim, considerou-se como restrição o valor mínimo para a CIR (8) e uma faixa de valores para a potência dos lasers (9). Neste caso, tal restrição apresenta justificativa prática: há limitação de potência máxima para o laser por um lado e ruído térmico no receptor que impede a redução da potência transmitida, no outro extremo. Uma CIR mínima faz-se necessária para garantir o QoS do sistema, ou seja para que as interferências de múltiplo 
acesso em redes OCDMA não levem a SNR de todos os usuários a níveis inferiores ao mínimo SNR determinado para cada classe de serviço.

Tendo em vista a seleção de soluções de vetores de potência que minimizam a potência total transmitida e simultaneamente garantam a mínima CIR , mantido os demais parâmetros do sistema como restrições, a função uni-objetivo em (7) pode ser modificada [18], [19] para:

$$
\begin{aligned}
& J(\mathbf{P})=\max \frac{1}{K} \sum_{i=1}^{K} F_{i}^{t h} F_{i}^{P} \\
& \text { s.t. } \quad 0 \leq p_{i} \leq P_{\max }
\end{aligned}
$$

onde

$$
F_{i}^{t h}=\left\{\begin{array}{cc}
1 & \Gamma_{i} \geq \Gamma^{*} \\
0 & c . c .
\end{array} \quad, \quad \text { e } \quad F_{i}^{P}=\left(1-\frac{p_{i}}{P_{\max }}\right)\right.
$$

sendo $F_{i}^{t h}$ uma função de threshold definida para o usuário $i$. Tal função limita o espaço de busca para soluções que maximizem o QoS médio, enquanto que $F_{i}^{P}$ valoriza soluções que utilizam mínima potência e pune outras que utilizam um nível mais elevado de potência.

Modificação foi introduzida na função custo em (21), tendo em vista alcançar a convergência em situações de alto carregamento de sistema e em condições de canal bastante díspares, resultando em:

$$
J(\mathbf{P})=\max \frac{1}{K} \sum_{k=1}^{K} F_{k}^{t h}\left(1-\frac{p_{k}}{P_{\max }}\right)+\frac{\rho}{\sigma_{r p}}
$$

A inclusão do segundo termo em (23) atribui crédito às soluções com pequeno desvio padrão para a distribuição de potência recebida normalizada, selecionando as soluções com $N F R \rightarrow$ 0 . Observe-se que com a inclusão desse segundo termo na função custo, obteve-se melhoria de convergência em relação ao problema orginalmente descrito em (21).

Nas próximas subseções serão descritas duas metodologias distintas para se resolver o mesmo problema de alocação de recursos em redes p-OCDMA, particularmente o problema da minimização de potência tendo a taxa de bits dos usuários p-OCDMA como restrição. Assim, soluções para esta classe de problema são obtidas e comparadas, a partir das abordagens inteligência swarm e equação iterativa de Verhulst, tendo como métrica o compromisso qualidade das soluções versus complexidade de implementação.

\subsection{Controle de Potência Óptico via Modelo de Verhulst}

O modelo de Verhulst, anteriormente empregado na solução do problema de controle de potência em sistemas OCDMA unitaxas [1], bem como em sistemas de comunicação sem 
fio unitaxas $[9,10]$, é estendido aqui para o cenário das comunicações CDMA ópticas com configuração estrela e usuários multitaxa.

Originalmente, o modelo de Verhulst foi proposto para descrever o crescimento populacional de indivíduos de uma determinada espécie biológica, em um ambiente com limitações de alimento e espaço físico (recursos disponíveis). Isto faz com que a população cresça até atingir um equilíbrio, cujo ponto é função da quantidade de recursos disponíveis. O modelo dinâmico atribuído à Verhulst [20] pode ser descrito pela equação diferencial:

$$
\dot{p}=z(p)=p\left(1-\frac{p}{p^{*}}\right)
$$

Integrando-se analiticamente a equação (24) obtém-se,

$$
p(t)=\frac{\exp (t) p(0) p^{*}}{p^{*}+p(0)[\exp (t)-1]}
$$

cujo comportamento assintótico é,

$$
\lim _{t \rightarrow+\infty} p(t)=p^{*}
$$

Verifique-se que para qualquer condição inicia, $\mathrm{p}(0)$ estritamente positiva. Quando $p(0)$ for maior que $p^{*}$ (o sinal de $d p / d t$ será negativo), $p(t)$ irá diminuir conforme $p(+\infty)=p^{*}$. Para o sinal $d p / d t$ positivo, $p(t)$ aumentará até que $p(+\infty)=p^{*}[1,10]$.

A versão discreta implementável para o modelo populacional de Verhulst, em termos da atualização das potências dos $K$ usuários em uma rede de múltiplo acesso, é descrita por $[9,10]$ :

$$
p_{i}(n+1)=(1+\alpha) p_{i}(n)-\alpha\left[\frac{\Gamma_{i}(n)}{\Gamma_{i}^{*}}\right] p_{i}(n), i=1, \ldots, K .
$$

sendo $0<\alpha \leq 1$ o fator responsável pela velocidade de convergência (valores de $\alpha$ próximo de 1 indicam convergência rápida) e simultaneamente determina a qualidade da solução (após a convergência) em termos de erro quadrático médio em relação a $p_{i}^{*}$.

Tal procedimento até o equilíbrio é diretamente aplicável ao problema do controle de potência distribuído descrito na Seção 3, caracterizando uma abordagem uni-objetivo. Maiores detalhes relativos à convergência do algoritmo de Verhulst foram discutidos em [9]. Doze proposições relativas à convergência do algoritmo de Verhulst foram desenvolvidas. Portanto, a comprovação teórica de convergência para o DPCA de Verhulst não será tratada aqui. 


\subsection{Controle de Potência Óptico via Inteligência Swarm}

A utilização de inteligência computacional na resolução de diversos problemas de otimização em engenharia, tem recebida muita atenção nos últimos anos. Descreve-se a seguir o princípio da otimização por nuvem de partículas (PSO - particle swarm optmization) aplicado ao problema do controle de potência em redes p-OCDMA utilizando abordagem de otimização uni-objetivo (SOO).

A heurística PSO utiliza como inspiração o comportamento social de um bando de aves, onde uma população é gerada para fazer a busca pela melhor solução. Considerando que o espaço de busca é $K$-dimensional, a $i$-ésima partícula é representada por um vetor posição $K$-dimensional $\mathbf{x}_{i}=\left[x_{i 1}, x_{i 2}, \ldots, x_{i K}\right]$ e à melhor partícula do bando, isto é, a partícula associada ao ótimo global ${ }^{5}$ obtida avaliando-se a função custo (23) até a presente iteração, é designada o índice $g$ e representada por $\mathbf{b}_{g}=\left[b_{g 1}, b_{g 2}, \ldots, b_{g K}\right]$. De forma análoga, o ótimo local atingido individualmente em cada elemento do vetor candidato $\mathbf{x}_{i}$, i.e. melhor posição individual ${ }^{6}$ atingida pelo $k$-ésimo elemento da $i$-ésima partícula até a iteração anterior é representada por $\mathbf{b}_{i}=\left[b_{i 1}, b_{i 2}, \ldots, b_{i K}\right]$, sendo a mudança de posição (velocidade) da $i$-ésima partícula é $\mathbf{v}_{i}=\left[v_{i 1}, v_{i 2}, \ldots, v_{i K}\right]$.

A atualização da velocidade e posição da partículas que compõem a população (ou bando) na $n$-esima iteração é obtida, em sua versão escalar, de acordo com:

$$
\begin{gathered}
v_{i K}[n]=w v_{i K}[n-1]+c_{1} r_{1}\left(b_{i K}-x_{i K}\right)+c_{2} r_{2}\left(b_{g K}-x_{i K}\right) \\
x_{i K}[n]=x_{i K}+v_{i K}[n]
\end{gathered}
$$

sendo $i=1,2, \ldots, \mathcal{P}$, com $\mathcal{P}$ o tamanho da população considerada em cada iteração; $w$ representa a inércia da partícula e controla a sua capacidade de exploração do espaço de soluções; um valor pequeno privilegia buscas locais, enquanto um valor elevado para este parâmetro amplia o universo de busca. Os valores mais utilizados na literatura encontram-se na faixa $[0,4 ; 1,4]$. O coeficientes de aceleração $c_{1}$ e $c_{2}$ são os parâmetros de confiança e definem o peso que o conjunto atribui a soluções individuais (i.e., se $c_{1}>c_{2}$ ), ou o oposto, atribui-se mais importância para a solução global encontrada pelo bando ( $\operatorname{se} c_{2}>c_{1}$ ). Classicamente, na literatura comumente assumem valores idênticos $c_{1}=c_{2}=2$. Adicionalmente, $r_{1}$ e $r_{2}$ são números aleatórios uniformemente distribuídos no intervalo [0;1]. As equações em (28) são utilizadas para determinar a nova velocidade da $i$-ésima partícula a cada iteração e a nova posição da $i$-ésima partícula, adicionando sua nova velocidade à sua posição atual, respectivamente. A população inicial é gerada aleatoriamente [21] dentro do intervalo $\left[x_{\min } ; x_{\max }\right]$.

\footnotetext{
${ }^{5}$ Maior ou menor valor da função custo, dependendo da otimização considerada. No caso do problema tratado aqui, busca-se a maximização em (23).

${ }^{6}$ Considerando o histórico individual da $k$-ésima partícula.
} 
Para o problema considerado, este intervalo representa a potência mínima e máxima associada ao laser do transmissor óptico. Adicionalmente, nas simulações computacionais foram utilizados valores para a inércia $w \in[0,1 ; 0,9]$. Considerou-se ainda que a velocidade $v_{i K}$ de cada partícula é limitada segundo um valor máximo e um mínimo, assumidos iguais aos valores de potências máxima e mínima, respectivamente, associadas (restrições) ao problema. Para os coeficientes de aceleração adotou-se valor típico encontrada na literatura, $c_{1}=c_{2}=2$. A Tabela 1 sumariza os principais parâmetros de entrada adotados nas simulações.

Table 1. Parâmetros de entrada do PSO para o Sistema p-OCDMA

\begin{tabular}{ll}
\hline Parâmetro & Valores Adotados \\
\hline \hline Número de usuários & $K \in[5 ; 10 ; 15 ; 31]$ \\
Aceleração local e global & $c_{1}=c_{2}=2$ \\
Inércia, $w$ & {$[0,1 ; 0,9]$} \\
Potências do Laser & $P_{\max }=5 \mathrm{dBm} ; \quad P_{\min }=-40 \mathrm{dBm}$ \\
População Inicial & $\mathbf{x}_{i K}[0] \sim \mathcal{U}\left[P_{\min } ; P_{\max }\right], \quad i=1, \ldots \mathcal{P}$ \\
Velocidade, $v_{i K}$ & $v_{\max }=P_{\max }-P_{\min } ; \quad v_{\min }=-v_{\max }$ \\
\hline
\end{tabular}

As etapas do funcionamento do algoritmo PSO, em sua versão contínua, podem ser observadas pelo fluxograma da Fig. 4, e o respectivo pseudo-código para o problema do controle de potência empregando abordagem heurística swarm com otimização uni-objetivo é descrito no Apêndice, Algoritmo 1.

\section{Resultados de Simulação}

As simulações foram feitas em ambiente MatLab, utilizando os parâmetros de sistema OCDMA estrela indicados na Tabela 2. Inicialmente, a potência ótima dos lasers para o problema do controle de potência particionado foi obtida para cada um dos $K$ usuários via inversão de matriz, obtendo-se o vetor $\mathbf{P}^{*}$ através da equação (13).

A qualidade da solução atingida pela estratégia de otimização (Vershulst ou PSO) pode ser medida através da distância da solução encontrada em relação ao valor das potências ótimas $\mathbf{P}^{*}$. Esta distância pode ser quantificada por meio do erro quadrático médio normalizado (normalized mean square error, NMSE), quando a convergência é atingida:

$$
N M S E[n]=\mathbb{E}\left[\frac{\left\|\mathbf{p}[n]-\mathbf{p}^{*}\right\|^{2}}{\left\|\mathbf{p}^{*}\right\|^{2}}\right],
$$


Inteligência Swarm e Equilíbrio de Verhulst Aplicados à Alocação de Potência em Redes Ópticas CDMA Particionadas

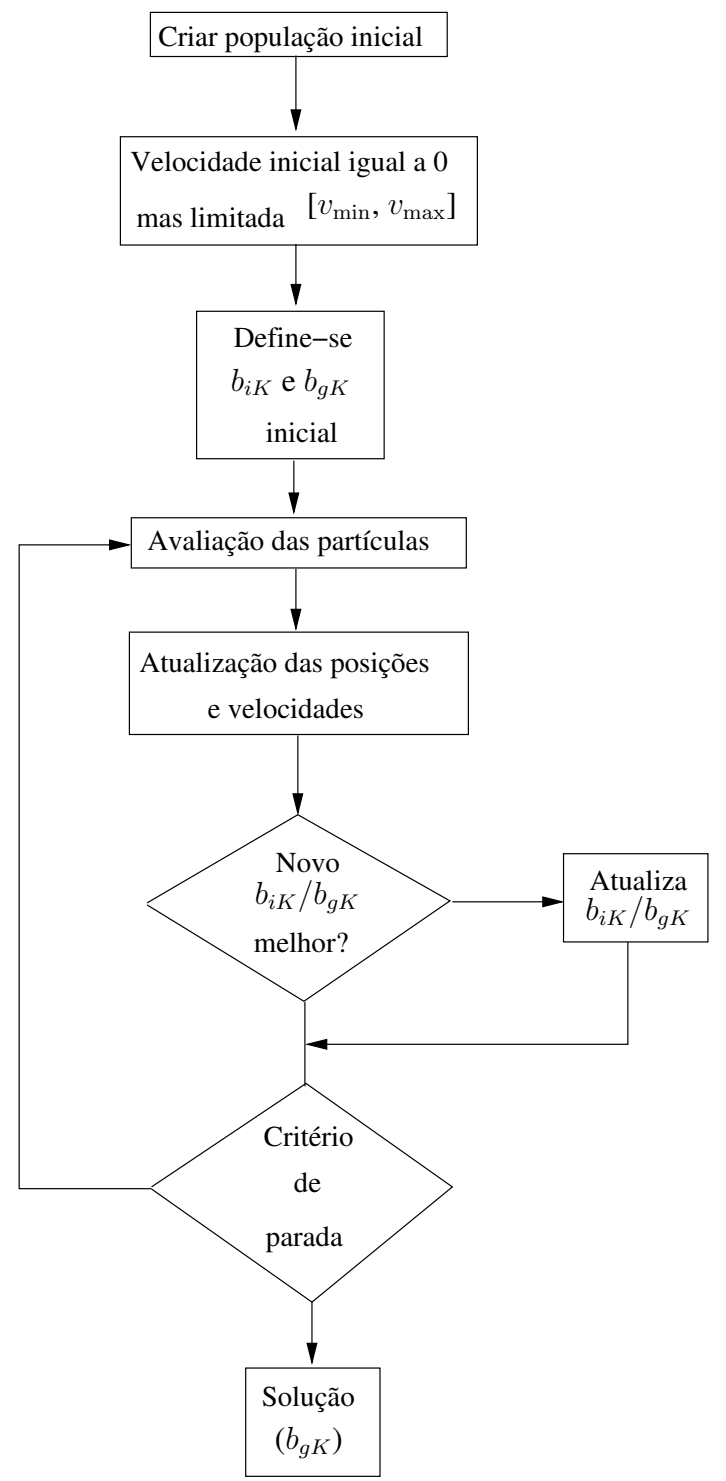

Figure 4. Fluxograma para o DPCA-PSO. 
Inteligência Swarm e Equilíbrio de Verhulst Aplicados à Alocação de Potência em Redes Ópticas CDMA Particionadas

onde $\|\cdot\|^{2}$ denota a distância Euclidiana quadrática em relação a origem e $\mathbb{E}[\cdot]$ o operador de esperança matemática.

Adicionalmente, um critério de parada pode ser estabelecido dado um erro máximo:

$$
\left|\frac{J[n]-J[n-1]}{J[n]}\right|<\epsilon_{\text {stop }}
$$

onde $J[n]$ e $J[n-1]$ são os valores da função custo na $n$-ésima e $n+1$-ésima iteração, respectivamente, e usualmente $\epsilon_{\text {stop }} \in[0.001 ; 0.01]$.

De maneira alternativa, com o intuito de avaliar a convergência dos algoritmos considerando um numero máximo de iterações $N$ ao longo de $T R$ realizações, o seguinte teste é considerado:

$$
\left|J[n]-J\left[\mathbf{p}^{*}\right]\right|<\epsilon_{1} J\left[\mathbf{p}^{*}\right]+\epsilon_{2}
$$

onde, $J\left[\mathbf{p}^{*}\right]$ é o ótimo global da função objetivo, $J[n]$ é o valor da função custo na iteração $n$ e $\epsilon_{1}$ e $\epsilon_{2}$ são coeficiêntes de precisão cujos valores típicos estão entre $10^{-1}$ e $10^{-5}$. Neste artigo consideramos $T R=100$ realizações e $\epsilon_{1}=\epsilon_{2}=2 \times 10^{-2}$.

\subsection{Controle de Potência via Verhulst}

A Fig. 5 exemplifica uma situação típica para $K=31$ usuários, e a Fig. 6 apresenta a evolução das potências alocadas para os 31 nós (linhas cheias) segundo a aplicação decorrente da equação (27), considerando $n=1,2,3, \ldots, 800$ iterações. O sistema analisado considera uma rede com nós distribuídos uniformemente distantes entre 2 e $50 \mathrm{~km}$ do acoplador estrela, máxima potência do laser de $20 \mathrm{dBm}$ para cada nó; desprezou-se o efeito da dispersão e não-linearidade da fibra. Observa-se que para valores reduzidos do fator de convergência, $\alpha=0,1$ na Figura 6.a, são necessárias de 600 a 800 iterações para o algoritmo atingir os respectivos valores das potências ótimas obtidos via (13), indicados pelas linhas pontilhadas na figura. À medida que $\alpha \rightarrow 1$, o algorithmo de controle de potência de Verhulst converge mais rapidamente para o vetor de potência ótimo às custas de uma redução na qualidade da solução [9], necessitando porém um menor número de iterações, conforme indicado na Fig. 6.b.

Assim, pôde-se verificar que com o controle de potência os nós mais distantes (usuários: $2,4,8,14,15,28$, por exemplo) recebem mais potência do que os nós mais próximos ao acoplador estrela (usuários: 3, 13, 17, 19, 24, 31, por exemplo), ao invés de todos receberem a mesma potência, o que causaria uma grande quantidade de MAI no receptor, diminuindo assim a capacidade do sistema.

As potências obtidas a cada iteração via modelo de Verhulst, na Fig. 6, foram comparadas com a solução da potência ótima $\left(\mathbf{P}^{*}\right)$, obtida analiticamente em (13). Nota-se que 
Inteligência Swarm e Equilíbrio de Verhulst Aplicados à Alocação de Potência em Redes Ópticas CDMA Particionadas

Table 2. Parâmetros de simulação do Sistema OCDMA Estrela Particionado

\begin{tabular}{ll}
\hline \multicolumn{1}{c}{ Parâmetro } & Valores Adotados \\
\hline \hline \multicolumn{2}{c}{ Sistema } \\
\hline Seq. Espalham. Prime, q & 31 \\
$\sigma_{C C}^{2}$ & 0,29 \\
Taxa de dados & $2,5 \mathrm{~Gb} / \mathrm{s}$ \\
Pot. laser disponível & $P_{\max }=20 \mathrm{dBm}$ \\
& $P_{\min }=0,01 P_{\max }$ \\
\# us. Tx & 31 \\
\# us. Rx & 31 \\
Distância Tx-Acoplador & $\sim \mathcal{U}[2,50] \mathrm{Km}$ \\
\hline \multicolumn{2}{c}{ Fibra Óptica } \\
\hline Comprimento de Onda & $1550 \mathrm{~nm}$ \\
$\gamma$ & $0,2 \mathrm{~dB}$ \\
$a$ & $0,2 \mathrm{~dB} / \mathrm{km}$ \\
\hline \multicolumn{3}{c}{ Tipo } \\
$\alpha$
\end{tabular}

independentemente da potência inicial atribuída a cada laser, assumida uma variável aleatória uniformemente distribuída no intervalo $\left[P_{\min } ; P_{\max }\right]$, a aplicação da equação (27) permite obter a convergência das potências dos lasers para as respectivas potências ótimas após um determinado número de iterações, função do parâmetro $\alpha$. À medida que $\alpha(0<\alpha \leq 1)$ cresce, a velocidade de convergência é melhorada. No entanto, a qualidade da solução, isto é, o erro quadrático normalizado em relação à potência ótima analítica, $P^{*}$, tende a aumen$\operatorname{tar}[9]$.

Para efeito de comparação, a Fig. 5.c indica a faixa dinâmica, em dB, para a matriz de interferência normalizada $\mathbf{H}$, correspondente à configuração do sistema. Na configuração adotada, cujas distâncias entre os lasers Tx e o acoplador estrela assumem valores uniformente distribuídos entre $2 \mathrm{Km}$ e $50 \mathrm{Km}$, a matriz $\mathbf{H}$ resulta em valores na faixa de aproximadamente $\pm 5 \mathrm{~dB}$. Por fim, a Fig. 5.b indica as correspondentes distâncias entre receptor e acoplador; conforme discutido anteriormente, após o acoplador estrela, não há ocorrência de interferência de múltiplo acesso (MAI), não contribuindo, portanto, para o balanço de potência dos lasers transmissores, conforme já mostrado no decorrer do trabalho.

Outros resultados empregando o método de Verhulst para o controle de potência em redes p-OCDMA de taxa única são discutidos em [1]. 
Inteligência Swarm e Equilíbrio de Verhulst Aplicados à Alocação de Potência em Redes Ópticas CDMA Particionadas
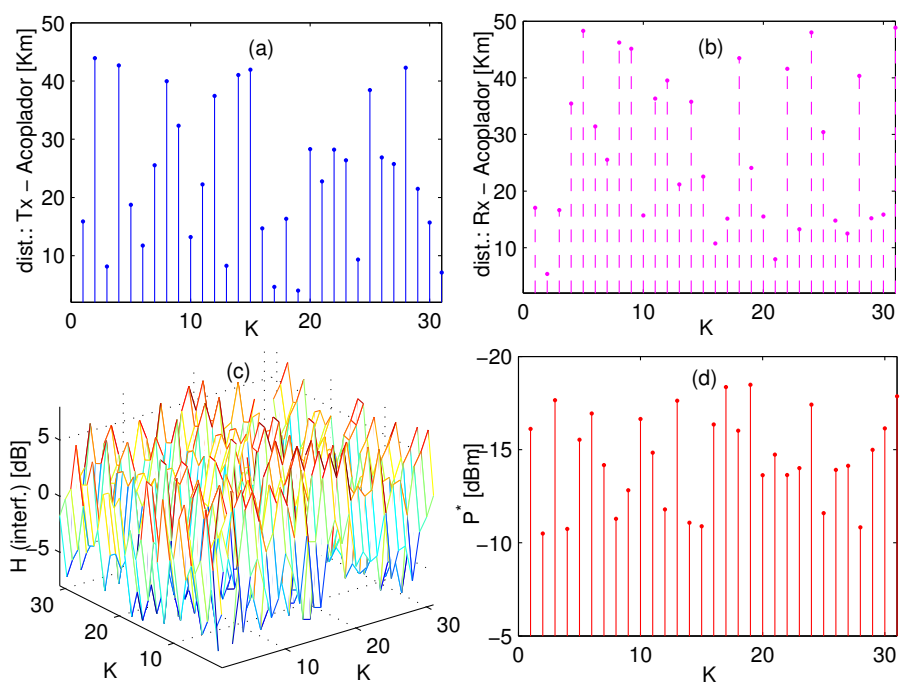

Figure 5. Comprimento das fibras dos nós a) transmissores e b) receptores até o acoplador estrela, c) matriz interferência $\mathbf{H}$ e d) potência ótima dos lasers com controle de potência particionado via $\mathbf{P}^{*}$, eq. (13).

\subsection{Controle de Potência com PSO}

Extensivas simulações foram realizadas tendo em vista a caracterização da região de convergência para o problema do controle de potência em sistema p-OCDMA empregandose abordagem heurística PSO. Inicialmente, analisou-se os valores dos parâmetros de entrada do algoritmo PSO, visando caracterizar o comportamento do algoritmo face às alterações nos valores desses parâmetros. Para cada configuração de parâmetros de entrada do PSO ( $c_{1}$, $c_{2}, \omega$ e $v_{\max }$ ), o algoritmo foi testado 10 vezes para análise de seu desempenho. Inicialmente, utilizou-se a função custo expressa em (21). Para $K=5$ usuários, $c_{1}=c_{2}=2$, $v_{\max }=1\left(P_{\max }-P_{\min }\right)$ e variando $w$ de 0,1 a 0,9 , houve convergência para os casos em que $w=0,5$ e $w=0,6$, conforme indicado Fig. 7. Para os demais casos, a convergência não foi garantida. Elevando-se o carregamento do sistema para $K=10$ usuários, comprovou-se que o valor ótimo para o parâmetro inércia permaneceu confinado no intervalo $w \in[0,5 ; 0,6]$, com um incremento na faixa de valores NMSE, como esperado. No entanto, com o aumento do número de interferentes no sistema óptico $(K \rightarrow 31)$, há perda de capacidade do PSO convergir para o vetor de potências ótimo, indicando a não convexidade do problema e portanto a necessidade de modificar a função custo (21).

Utilizando a função custo uni-objetiva modificada da eq. (23) obteve-se os resultados de desempenho discutidos a seguir. Para tanto, realizou-se uma nova otimização dos 
Inteligência Swarm e Equilíbrio de Verhulst Aplicados à Alocação de Potência em Redes Ópticas CDMA Particionadas
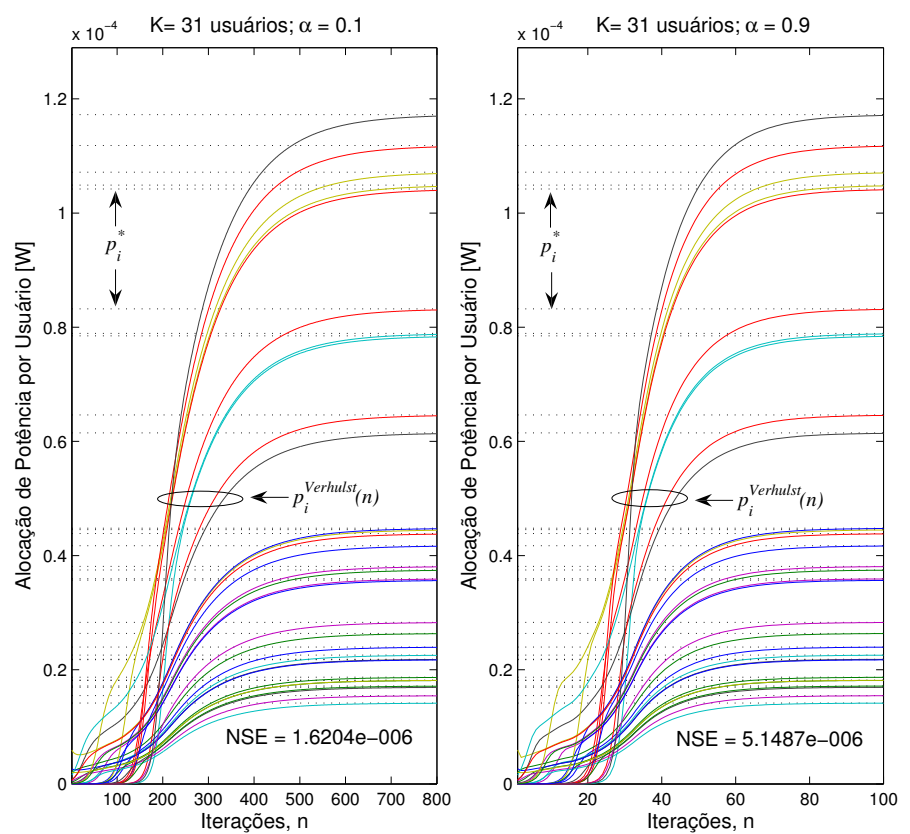

Figure 6. Curvas da convergência da potência inicial de cada laser para sua respectiva potência ótima e cálculo da NMSE: $p_{i}(n \rightarrow \infty)=p_{i}^{*}, i=1,2, \ldots, 31$. a) $\alpha=0,1$ e $N M S E=1,62 \times 10^{-6}$; b) $\alpha=0,9$ e $N M S E=5,15 \times 10^{-6}$. 
Inteligência Swarm e Equilíbrio de Verhulst Aplicados à Alocação de Potência em Redes Ópticas CDMA Particionadas
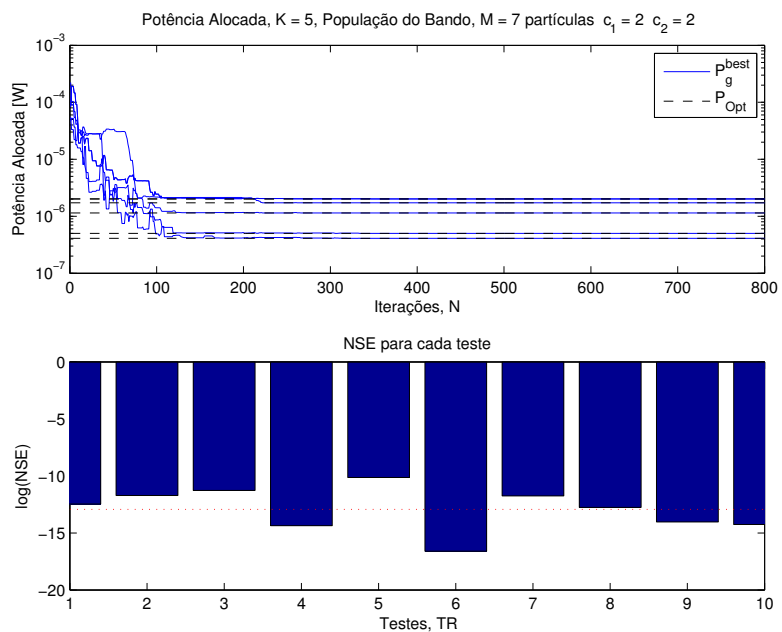

Figure 7. Busca das partículas pela potência ótima com $w=0,5$ e a NMSE para a solução analítica.

parâmetros de entrada para o algoritmo PSO, conforme Tabela 3.

Table 3. Parâmetros de entrada do PSO, para a função custo (23)

\begin{tabular}{ll}
\hline Parâmetro & Valores Adotados \\
\hline Número de usuários & $K \in[2 ; 31]$ \\
Aceleração local e global & $c_{1}=c_{2}=2$ \\
Inércia & $w=0,6$ \\
População Inicial & $\sim \mathcal{U}\left[P_{\min } ; P_{\max }\right]=[-20 ;-5] \mathrm{dBm}$ \\
Velocidade & $v_{i K} \in\left[v_{\min } ; v_{\max }\right]$ \\
& $v_{\max }=\frac{P_{\max }-P_{\min }}{50}, \quad v_{\min }=-v_{\max }$ \\
Tamanho da População & $\mathcal{P} \in[K ; 10 K]$ \\
\hline
\end{tabular}

Com o aumento do número de usuários, há também um acréscimo no número de iterações até a convergência e no tamanho da população do bando, gerando um inevitável aumento na complexidade computacional. À medida que $K$ aumenta, a CIR mínima para garantir o QoS mínimo também se eleva. Esta condição deve ser satisfeita para se garantir a convergência.

Resultados de simulação para o sistema p-OCDMA com 31 usuários indicaram consistência do vetor de potência otimizado via eq. (28), com valores de NMSE na faixa de $\approx\left[10^{-5} ; 10^{-1}\right]$, todos os usuários apresentando CIR acima da mínima aceitável. 
Inteligência Swarm e Equilíbrio de Verhulst Aplicados à Alocação de Potência em Redes Ópticas CDMA Particionadas

Com a utilização de velocidades máxima e mínima muito pequenas (Fig. 8), obteve-se NMSEs bem abaixo de $10^{-1}$ para $K=31$ usuários. Observa-se que com limites de velocidade muito baixos, a NMSE final é menor; em contrapartida exige-se uma maior número de iterações para a convergência.
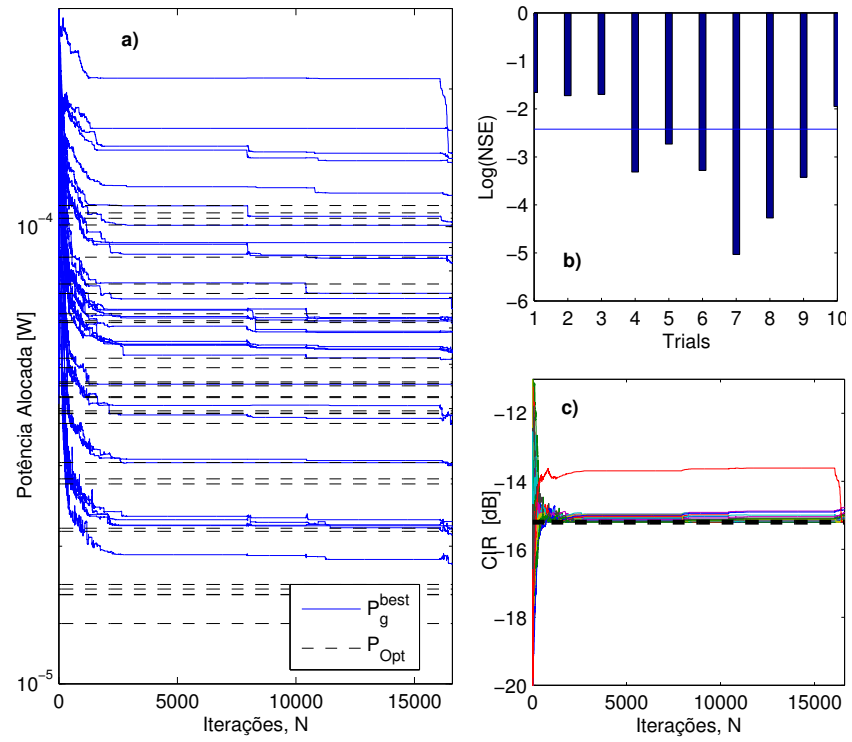

Figure 8. Convergência PSO para $K=31$ usuários e $\mathcal{P}=126$ partículas. a) Potência alocada a cada iteração. b) NMSE em 10 realizações; c) CIR a cada iteração

Por se tratar de um problema não-convexo combinado a um método de busca heurístico, a convergência para a solução ótima nem sempre é atingida, conforme indicado na Fig. 8, mesmo após um número considerável de iterações. A velocidade de convergência também depende do quão próximo o vetor de potência inicial (população inicial), assumido aleatório, está do vetor solução, $\mathbf{P}^{*}$, eq. (13). Observe que na Fig. 8.a, apesar da solução encontrada pela heurística PSO não coincidir com a solução ótima, o erro quadrático médio normalizado situa-se em patamares reduzidos (Fig. 8.b).

\section{Análise de Complexidade}

A complexidade dos algoritmos foi analizada levando em conta o número de operações matemáticas envolvidas no processo de solução do problema em relação ao número de usuários ativos no sistema $K$. Desta forma as equações (8), (23), (26), (28) e (29) foram 
Inteligência Swarm e Equilíbrio de Verhulst Aplicados à Alocação de Potência em Redes Ópticas CDMA Particionadas

avaliadas e a Tabela 4 mostra a quantidade de operações realizadas a cada iteração para cada uma das equações.

Table 4. Número de Operações por Equação a cada iteração.

\begin{tabular}{ccccc}
\hline DPCA & Equação & Somas & Multipl. & Inv. Matriz \\
\hline Verhulst, PSO & $(8)$ & $K^{2}+K$ & $2 K^{2}+2 K$ & 0 \\
\hline Verhulst & $(27)$ & $K+1$ & $2 K+2$ & 0 \\
\hline \multirow{2}{*}{ PSO } & $(23)$ & $2 K$ & $4 K$ & 0 \\
& $(28)$ & $5 K \times \mathcal{P}$ & $(3 K+2) \times \mathcal{P}$ & 0 \\
& $(29)$ & $K \times \mathcal{P}$ & 0 & 0 \\
\hline Matriz Inversa & $(13)$ & $K$ & $K^{2}$ & 1 \\
\hline
\end{tabular}

Observe que para as equações (23) e (27) o número de multiplicações depende diretamente do cálculo da CIR e portanto a complexidade da equação (8) deve ser somada. Para a solução analítica utilizando a inversão da matriz as multiplicações são da ordem de $K^{2}$. Além disto, a inversão da matriz é considerada de complexidade $K^{3}$ se calculada pelo algoritmo de eliminação de Gauss-Jordan. Considerou-se aqui que os tempos necessários para o cômputo de cada operação de soma, subtração, divisão e multiplicação são equivalentes. Adicionalmente, a complexidade computacional envolvida na geraração dos números $c_{1}$ e $c_{2}$ em (28), bem como no cálculo da função $F_{k}^{t h}$ em (23) foi considerada despresível, i.e. da ordem de $\mathcal{O}(1)$.

Sendo assim, é possível conjecturar que a solução analítica do problema tem complexidade computacional da ordem de $\mathcal{O}\left(K^{3}\right)$. O PSO por sua vez tem complexidade computacional equivalente a soma da complexidade das equações (23), (8), (28) e (29) e portanto equivalente a $\mathcal{O}\left(K^{2}+K \mathcal{P}\right)$, ou seja, para os $\operatorname{casos}^{7} \mathcal{P} \gg K^{2}$, a complexidade do PSO é da ordem de $\mathcal{O}(P)$, caso contrário $\mathcal{O}\left(K^{2}\right)$. Por fim, a solução baseada no equilíbrio de Verhulst tem complexidade computacional da ordem de $\mathcal{O}\left(K^{2}\right)$.

Note que a análise de complexidade acima refere-se a uma única iteração. Desta forma, um estudo acerca da convergência computacional para os dois algoritmos foi conduzido. A Fig. 9, indica o número médio de interações necessárias até a convergência para os algoritmos de Verhulst e PSO, obtido a partir de 100 realizações e para $K \in\{2,5,7,10,12,15\}$. Neste sentido, é importante observar que a convergência para carregamentos de sistema inferiores a 5 usuários é mais rápida no algoritmo PSO. Todavia, a complexidade exibida pelo algoritmo PSO neste quesito pode ser bem ajustada a um polinômio de terceiro grau enquanto o DPCA Verhulst é simplesmente linear.

Associando a análise de complexidade a cada iteração ao número médio de iterações

\footnotetext{
${ }^{7}$ Quando a dimensão do problema cresce, i.e., número elevado de usuários.
} 
Inteligência Swarm e Equilíbrio de Verhulst Aplicados à Alocação de Potência em Redes Ópticas CDMA Particionadas

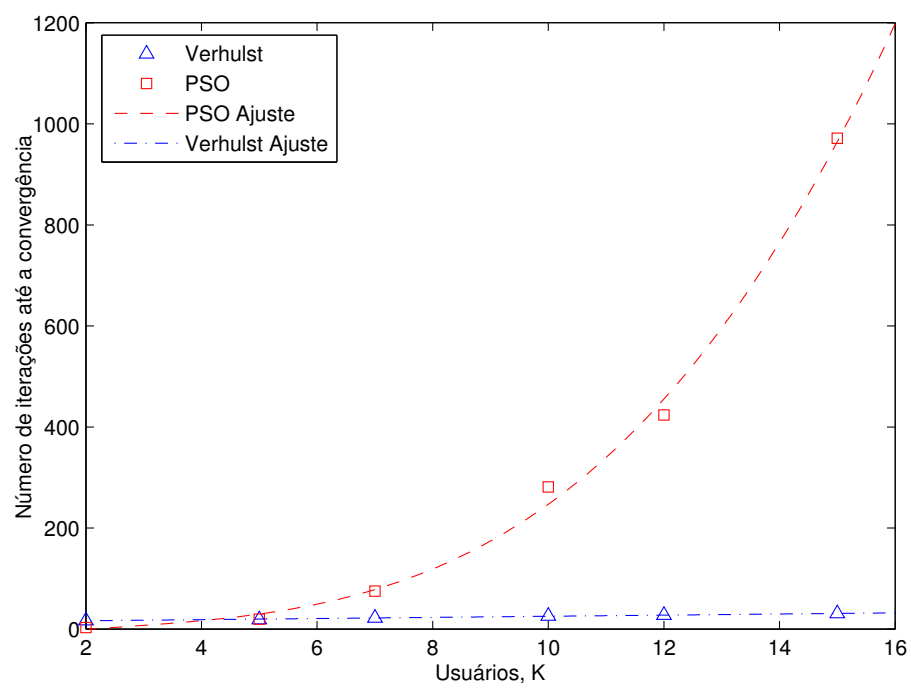

Figure 9. Teste de convergência para o DPCA Verhulst e para o PSO em relação ao número de usuários no sistema. Os ajustes foram calculados de maneira linear para Verhulst, com $y_{\text {Verh }}=1.12 x+14.14$, e cúbica para o PSO, com $y_{\mathrm{PSO}}=0.45 x^{3}-3.48 x^{2}+17 x-24.43$.

necessárias à convergência (obtido via ajuste de curvas), é possível avaliar o número total de operações necessárias em função do carregamento crescente do sistema. Este estudo está ilustrado na Fig. 10: forma considerados dois casos para o tamanho da população no PSO, $\mathcal{P}=K$ e $\mathcal{P}=10 K$. É evidente a maior complexidade da abordagem heurística quando comparada ao algoritmo iterativo de Verhulst, mesmo para um número de usuários muito reduzido $(K<5)$; isto se deve à maior quantidade de operações computacionais associada ao PSO. Assim, comparando-se os resultados de convergência e complexidade para as abordagens de Verhulst e PSO, Fig. 6 versus Fig. 8 e Fig. 10, claramente a abordagem analítica-iterativa de Verhulst apresenta figuras de mérito superiores em ambos os quesitos para qualquer carregamento de sistema.

\section{Conclusões}

Neste trabalho foram propostas duas abordagem para a realização do controle de potência óptico distribuído em redes particionadas OCDMA do tipo estrela. A primeira abordagem emprega o modelo analítico-iterativo de Verhulst, originalmente concebido para descrever o crescimento populacional sujeito à limitação de território e alimentos. O segundo 
Inteligência Swarm e Equilíbrio de Verhulst Aplicados à Alocação de Potência em Redes Ópticas CDMA Particionadas

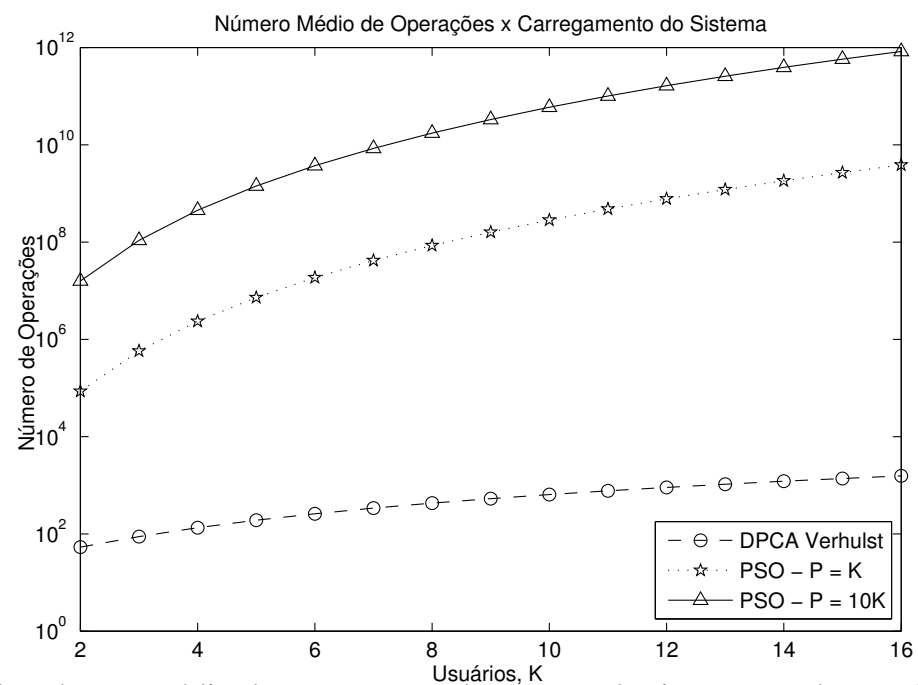

Figure 10. Número médio de operações até a convergência versus número de usuários, considerando polinômios de ajuste da Fig. 9 e complexidade da Tabela 4.

DPCA p-OCDMA proposto utiliza abordagem heurística baseada em inteligência swarm. A qualidade das soluções encontradas para o problema do controle de potência pôde então ser comparada a solução analítica, utilizando como figura de mérito o NMSE.

Observou-se que o controle de potência centralizado necessita de um nó central com informação sobre o ganho de todos os links ativos no sistema, enquanto no controle de potência particionado, cada usuário é equipado com informações relativas aos outros nós, permitindo uma apropriada distribuição de potência e por consequência um aumento na capacidade do sistema óptico. Uma vez que os enlaces ópticos após o acoplador estrela (relativos aos nós receptores) não influenciam no cálculo do controle de potência (a CIR encontrada à saída do acoplador estrela é praticamente a mesma encontrada nos nós receptores), pôde-se utilizar somente os parâmetros dos transmissores da fibra e do acoplador estrela.

Resultados numéricos de simulação indicaram similaridade na qualidade da soluções (NMSE similares) obtidas tanto pelo DPCA de Verhulst quanto via heurística PSO, em relação a solução analítica, para uma ampla faixa de carregamento do sistema e mesmo em presença de erros nas estimativas dos ganhos de canal óptico (atenuação e perdas no acoplador). Assim, um controle de potência distribuído, onde cada nó recebe a quantidade de potência mínima necessária para se atingir uma qualidade de serviço específica, é capaz de proporcionar um relativo aumento da capacidade do sistema devido à diminuição da MAI proporcionada pelo adequado balanço de potência nos lasers transmissores. No entanto, devido à 
natureza não-convexa do problema, a abordagem heurística resultou em maior complexidade computacional, dado tanto pela necessidade de um maior número de interações para o algoritmo atingir a convergência quanto pela maior número de operações intrínsecas a cada iteração, quando comparado ao algoritmo de Verhulst. Claramente, entre as duas abordagens propostas neste trabalho, o DPCA analítico-iterativo de Verhulst atingiu figuras de mérito superiores em todos os quesitos analisados, sendo portanto o mais adequado a integrar soluções tecnológicas para o controle de potência em sistemas p-OCDMA.

Trabalhos futuros incluem, no caso da abordagem heurística, a discretização do universo de busca, tendo em vista a redução da dimensão do problema e portanto da complexidade. Outro tópico em aberto e de extremo interesse consiste na reformulação do problema de alocação de recursos com múltiplos objetivos conflitantes sob a perspectiva da otimização multi-objetivo. Finalmente, o problema da alocação conjunta de potência e taxa em redes OCDMA (sob a perspectiva uni- ou multiobjetivo) considerando situações de canais dinâmicos (rápida alteração de tráfego das características de enlaces).

\section{Agradecimentos}

Este trabalho foi parcialmente financiado pela CAPES (bolsa DS), CNPq (303426/20098) e FAP-Araucária (045/2007). 
Inteligência Swarm e Equilíbrio de Verhulst Aplicados à Alocação de Potência em Redes Ópticas CDMA Particionadas

\section{Apêndice: Pseudo-Código}

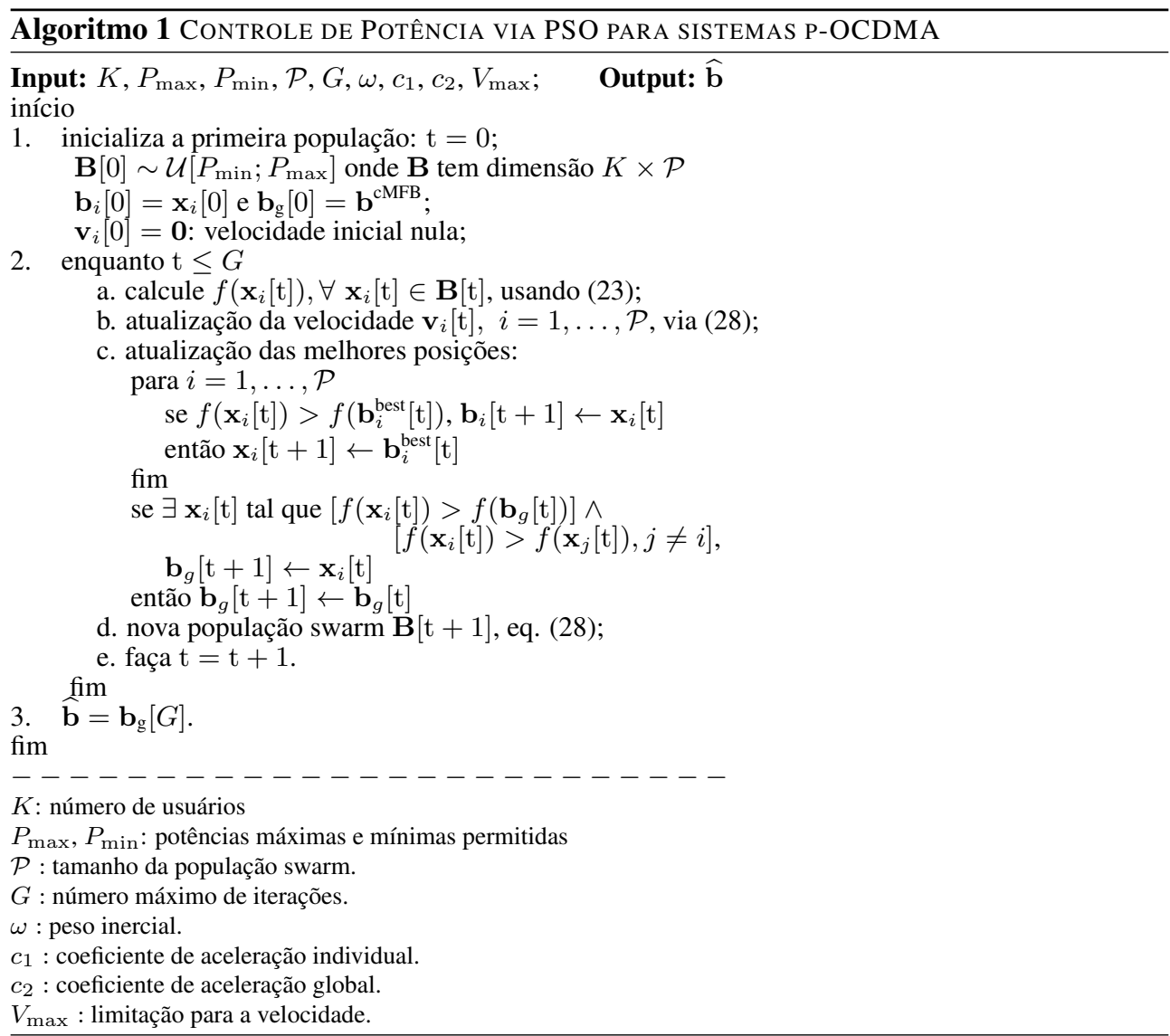

$10 *$

\section{References}

[1] M. S. Filho, F. Durand, F. Ciriaco, and T. Abrão, "Controle de potência em redes ocdma estrela de múltiplo acesso via modelo de verhulst," in XXVII Simpósio Brasileiro de Telecomunicações, Blumenau, SC, 29 Set- 02 Out. 2009, pp. 1-6. 
Inteligência Swarm e Equilíbrio de Verhulst Aplicados à Alocação de Potência em Redes Ópticas CDMA Particionadas

[2] P. R. Prucnal, Optical Code Division Multiple Access: Fundamentals and Applications. Taylor and Francis, 2006.

[3] R. Ramaswami and K. N. Sivarajan, Optical networks, a practical perspective. Morgan Kaufmann publishers, 1998.

[4] A. Stok and E. H. Sargent, "Lighting the local area: Optical code-division multipleaccess and quality of service provisioning," IEEE Network, vol. 14, no. 6, p. 42, Nov./Dec. 2000.

[5] H. Yashima and T. Kobayashi, "Ocdma with time-hopping and power control for multimedia networks," Journal of Lightwave Tech., vol. 21, no. 3, p. 695, March 2003.

[6] M. S. E. Naser G. Tarhuni and T. O. Korhonen, "Nonlinear power control for asynchronous fiber-optic cdma networks," in IEEE ICC 2006, June 2006, pp. 2782-2786.

[7] N. G. Tarhuni, M. S. Elmusrati, T. O. Korhonen, and E. Mutafungwa, "Multi-accessinterference mitigation using power control in optical-cdma star network," in IEEE International Conference on Communications, ICC'05, vol. 3, May 2005, pp. 1593-1597.

[8] J. F. H. Chao-Chin Yang and T.-C. Hsu, "Differentiated service provision in optical cdma network using power control," IEEE Photonics Technology Letters, vol. 20, no. 20, pp. 1664-1666, October 2008.

[9] T. J. Gross, T. Abrão, and P. J. E. Jeszensky, "Algoritmo de controle de potência distribuído fundamentado no modelo populacional de verhulst," Revista da Sociedade Brasileira de Telecomunicações, vol. 20, no. 2, pp. 59-74, 2006.

[10] — - "Distributed power control algorithm for multiple access systems based on verhulst model," AEU - International Journal of Electronics and Communications, vol. 65, no. 4, pp. 361-372, April 2011.

[11] L. H. Sampaio, M. F. Lima, B. B. Zarpelão, M. L. P. Jr, and T. Abrão, "Power allocation in multirate ds/cdma systems based on verhulst equilibrium," in ICC'10 - International Conference on Communications: Communications: Accelerating Growth and Development, Cape Town, South Africa, 2010, pp. 1-6.

[12] — "Swarm power-rate optimization in multi-class services ds/cdma networks," in 28o. Simpósio Brasileiro de Redes de Computadores e de Sistemas Distribuídos, Gramado, 2010, pp. 1-14.

[13] M. Elmusrati, H. El-Sallabi, and H. Koivo, "Applications of multi-objective optimization techniques in radio resource scheduling of cellular communication systems," IEEE Transactions On Wireless Communications, vol. 7, no. 1, pp. 343-353, 2008. 
Inteligência Swarm e Equilíbrio de Verhulst Aplicados à Alocação de Potência em Redes Ópticas CDMA Particionadas

[14] W. Kwong, P. Prucnal, and P. Perrier, "Synchronous versus asynchronous cdma for fiber-optic lans using optical signal processing," in Global Telecommunications Conference GLOBECOM 89, vol. 2, Nov. 1989, pp. 1012-1016.

[15] P. R. Prucnal, M. A. Santoro, and T. R. Fan, "Spread spectrum fiberoptic local area network using optical processing," Journal of Lightwave Technology, vol. 4, pp. 547554, May 1986.

[16] G. C. Yang and W. Kwong, "Performance analysis of optical cdma with prime codes," Electronics Letters, vol. 31, pp. 569-570, March 1995.

[17] M. S. Elmusrati, "Power control and mimo beamforming in cdma mobile communication systems," Helsink University of Technology, Report 129, August 2002.

[18] M. Moustafa, I. Habib, and M. Naghshineh, "Genetic algorithm for mobiles equilibrium," in MILCOM 2000. 21 st Century Military Communications Conference Proceedings, vol. 1, 2000, pp. 70-74.

[19] H. M. E. Hassan M. Elkamchouchi and M. A. Makar, "Power control in cdma system using particle swarm optimization," in 24th NATIONAL RADIO SCIENCE CONFERENCE (NRSC 2007), March 13-15 2007, pp. 1-8.

[20] P. F. Verhulst, "Notice sur la loi que la population poursuit dans son accroissement," Correspondance mathématique et physique, pp. 10:113-121, 1838.

[21] K. E. Parsopoulos and M. N. Vrahatis, Intelligent technologies: theory and applications. Greece: IOS Press, 2002. 